\title{
Failure Prediction of AISI 420 Martensitic Stainless Steel Using the Theory of Critical Distances
}

\author{
Marcelo de Oliveira Siqueira ${ }^{a *}$ (D), Eduardo Atem de Carvalho ${ }^{\text {(D) }}$ \\ ${ }^{a}$ Universidade Estadual do Norte Fluminense Darcy Ribeiro, Rio de Janeiro, RJ, Brasil
}

Received: October 25, 2020; Revised: December 3, 2020; Accepted: December 14, 2020

\begin{abstract}
This work aims to evaluate the capability of the theory of critical distances (TCD) to predict the static failure of U-notched AISI 420 martensitic stainless steel specimens with different geometric features under pure bending loading. Theoretical estimates of the stress intensity factor during fracture onset were calculated according to the line (LM) and point methods (PM), which consider the characteristic length $L$, inherent strength $\sigma_{0}$, and notch tip radius $\rho$. Initially, $L$ and $\sigma_{0}$ were determined on the basis of the material's properties (i.e., fracture toughness $K_{\mathrm{Ic}}$ and ultimate tensile strength $\sigma_{\mathrm{u}, \mathrm{t}}$ ), resulting in imprecise estimates. Conversely, $L$ and $\sigma_{0}$ determined using the appropriate analysis of linear-elastic stress fields ahead of notches with different sharpness provided highly accurate predictions. The microscopic study of fractured specimens ensured better comprehension of the results. Moreover, the accurate values of $L$ and $\sigma_{0}$ were used to predict the failure of V-notched specimens.
\end{abstract}

Keywords: Theory of critical distances, AISI 420, U-notch, V-notch, Small-scale yielding.

\section{Introduction}

On-service failure of a component or equipment consists of an extremely undesirable occurrence in any industrial field, which can result in loss of human life, environmental pollution, and extensive material damage. Thus, failure prediction techniques have an important role in the assessment of flaws (i.e., cracks, bulges, dents, and corrosion) and support the correct design of geometric features. Dimensional or shape variations, keyways, and notches are examples of geometric features that concentrate stresses around its apices during loading, consequently becoming the most probable regions of crack onset ${ }^{1}$.

In the past century, many investigations have proposed accurate methods for failure prediction of engineering materials in the presence of cracks and evaluation of the detrimental effects of notches on the general strength of components with different geometric attributes ${ }^{2}$. Despite the existence of well-established and standardized methods for failure prediction, considering different types of damages, researchers continue the search for rapid, inexpensive, and reliable methods. Among the currently discussed alternatives, the theory of critical distances (TCD) deserves special attention because of the simplicity of its mathematical formalization and accurate results obtained for different materials (i.e., ceramics, polymers, metals, and composites), geometries, and loading modes.

The present study evaluates the capability of TCD to predict the failure of U-notched AISI 420 specimens loaded under four-point bending and assesses the failure of $\mathrm{V}$-notched specimens under bending loading and tensile stress. The microscopic analysis of fractured specimens leads to a comprehensive understanding of the results obtained.

*e-mail: marcelo.osiqueira@pq.uenf.br

\section{Literature Review}

\subsection{Theory of critical distances}

TCD employs four methods to predict failure in the vicinity of local stress concentrators through the analysis of linear-elastic stress fields. The four methods directly related to TCD are line method (LM), point method (PM), area method, and volume method, which commonly use a basic parameter called characteristic length $L$ for failure prediction ${ }^{2}$. In the late $1930 \mathrm{~s}, \mathrm{Neuber}^{3}$ first proposed a methodology for evaluating high-cycle fatigue based on a length scale parameter. Neuber determined that the effective stress that leads to failure is the average elastic stress ahead of a stress raiser over a material-dependent length. This initial approach resulted in the LM. A few years later, Peterson ${ }^{4}$ presented the PM, which is a simplification of Neuber's proposal. According to Peterson's proposal, the failure of a notched material under high-cycle fatigue occurs when the elastic stress reaches a critical value at a characteristic distance from the stress concentrator apex. After these initial works, a breakthrough in the theoretical formulation of TCD was achieved when Whitney and Nuismer ${ }^{5}$ linked continuum mechanics to linear-elastic fracture mechanics (LEFM), deriving an equation that estimates the characteristic length $L$ as a function of material plane strain fracture toughness $K_{\text {Ic }}$. Whitney and Nuismer ${ }^{5}$ evaluated the stress distribution in laminated composite specimens containing throughthickness circular holes and straight cracks by conducting uniaxial tensile tests.

More recently, Taylor ${ }^{6-8}$ reassessed the original formulations of TCD methods, providing a new interpretation based on several papers of different authors, which encompass a wide range of materials, loading modes, and fracture behavior. Taylor's work prompted novel research on TCD methods ${ }^{9,10}$, which elicited new and diverse data from different materials, 
corroborating the capability of TCD to provide accurate predictions under diverse conditions.

Despite the results of recent studies, the reasons why TCD works so well for different materials are continuously discussed. Taylor ${ }^{7}$ stated that theories used to predict failure can be organized in a spectrum, which has in one extreme continuum mechanics theories (i.e., LEFM) and in the other extreme micro-mechanistic approaches (i.e., Ritchie-KnottRice model). Given this spectrum, TCD is in the middle and becomes slightly closer to the first extreme once it is utilized to modify LEFM. In TCD the presence of mechanisms that occur in the microstructural level is denoted by the characteristic length parameter $L$.

In addition to this general effort to understand the mechanisms related to TCD, a specific issue arises and continues to intrigue researchers, i.e., if TCD is based on principles related to LEFM, then why does it obtain accurate results for materials with elastic-plastic behavior? Although accurate results are obtained, this question stands open in the conclusion of many studies, either in the case of smallscale $^{11}$ or large-scale ${ }^{12,13}$ plastic deformation.

\subsection{AISI 420 stainless steel}

AISI 420 selected for this work is martensitic stainless steel used for industrial applications and typically has a carbon content between $0.15 \mathrm{wt} \%$ and $0.40 \mathrm{wt} \%$. Moderate corrosion resistance is achieved with the addition of $12 \mathrm{wt} \%$ to $14 \mathrm{wt} \%$ chromium $^{14}$.

Similar to other martensitic stainless steels, AISI 420 is generally supplied in the spheroidized condition, i.e., its microstructure consists of a ferrite matrix and uniformly distributed coarse carbides. Common thermal processing of this steel includes annealing, austenitizing, oil quenching, and tempering ${ }^{15}$. According to the heat treatment history, the final microstructure may contain different percentages of martensite, metallic carbides $\left(\mathrm{M}_{x} \mathrm{C}_{y}\right)$, and retained austenite over a ferritic matrix. As a consequence of many possible microstructural compositions, a wide range of mechanical properties can be obtained, enabling several applications for this material, such as valve parts, turbine blades, cutting tools, pressure vessels, dental and surgical instruments, and plastic molding. Despite the improvement of toughness through tempering, in some cases, AISI 420 is applied in the annealed or as-quenched condition ${ }^{15-17}$.

\subsection{Linear-elastic stress field ahead of blunted cracks}

In this work, the stress field ahead of a U-notch will be defined according to Creager and Paris's original equations ${ }^{18}$ for Mode I opening, which are based on LEFM. These authors presented equations describing the stress field ahead of a blunted crack to analyze the arresting effect over a stress corrosion crack because of the blunting of the crack tip associated with the dissolution phenomenon. Figure 1 depicts the coordinate system used by the authors, of which the origin is located behind the crack tip at a distance $r_{0}=\rho / 2$, where $\rho$ is the blunted crack root radius.

Given that a blunted crack is geometrically similar to a notch, Creager and Paris's ${ }^{18}$ approach yields an approximate prediction of the stress field for notches with root radius $\rho$. Equation 1 expresses the stress field for a specific condition where $\theta=0$ is considered because the stress field of interest is located right ahead of the notch tip.

$\sigma_{\theta \theta}(r)=\frac{K_{I}^{U, \rho}}{\sqrt{2 \pi r}}\left[1+\frac{\rho}{2 r}\right]$

In Equation 1, $K_{I}^{U, \rho}$ is the Mode I stress intensity factor for a U-notch with root radius $\rho$ and $r$ is the distance from the origin in the adopted coordinate system.

\section{Failure Criteria-Point and Line Methods}

The present work investigates two criteria associated with TCD, i.e., PM and LM. Figure 2 illustrates the working principles of these methods.

In Figure 2, $L$ is the characteristic length of the material and a basic parameter of TCD and $\sigma_{0}$ is the inherent strength of the material. Characteristic length applied to static loading can be calculated using Equation $2^{12}$, where $K_{\mathrm{Ic}}$ is the plane strain fracture toughness. This relation is derived from the study of Whitney and Nuismer ${ }^{5}$.

$L=\frac{1}{\pi}\left(\frac{K_{I c}}{\sigma_{0}}\right)^{2}$

As previously mentioned, PM states that static failure occurs when the effective stress $\sigma_{\text {eff }}$ ahead of the notch tip

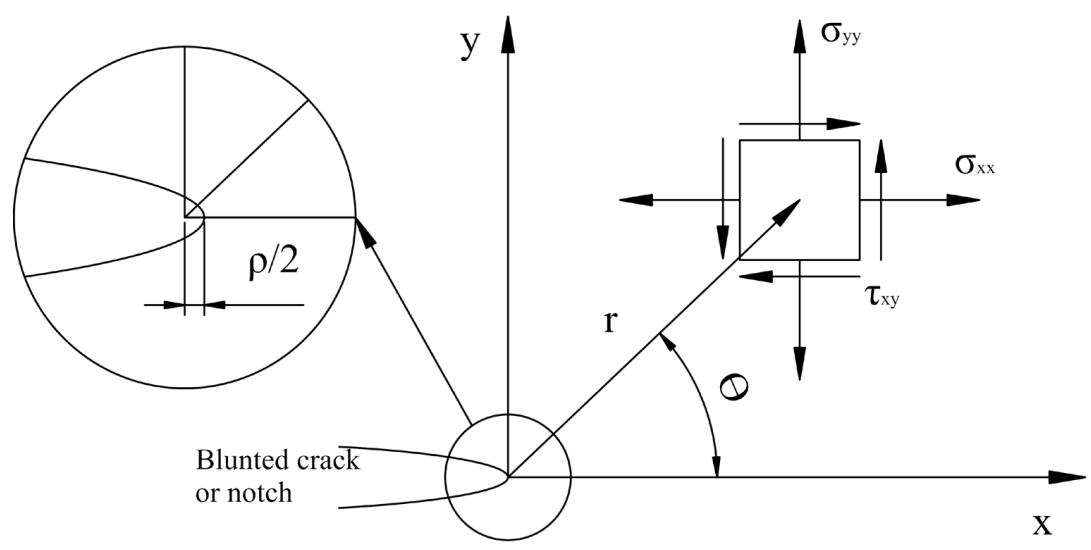

Figure 1. Coordinate system considered by Creager and Paris ${ }^{18}$. 


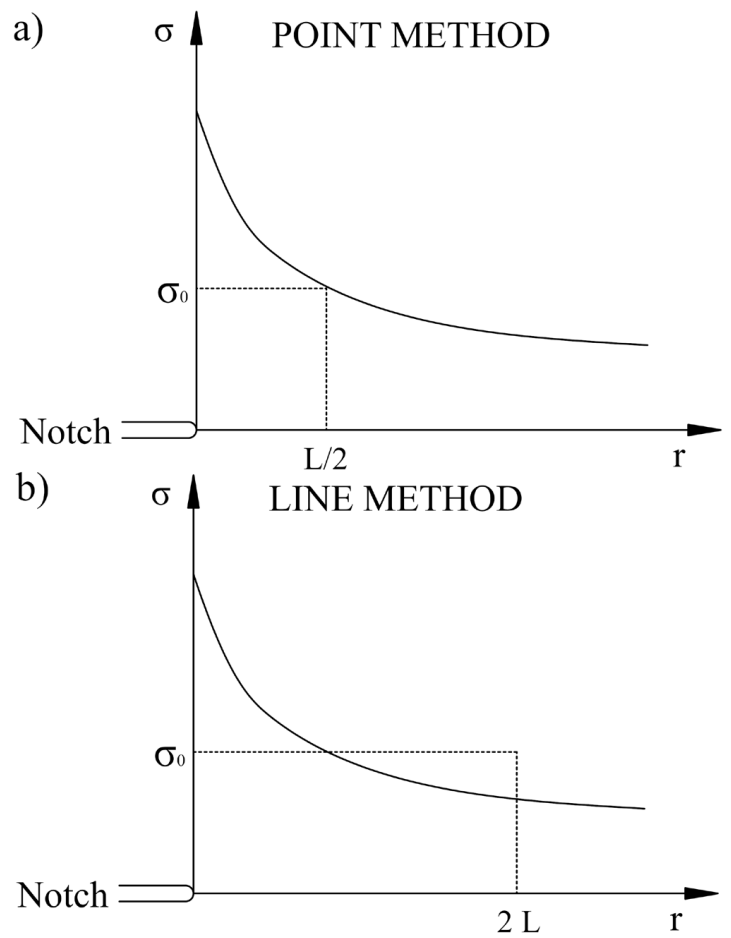

Figure 2. Graphical representation of the working principles of (a) PM and (b) LM.

exceeds the inherent strength of the material $\sigma_{0}$ at a distance $L / 2$ from the tip (Figure 2a). Equation 3 expresses the mathematical formalization of $\mathrm{PM}^{12}$.

$$
\sigma_{e f f}=\sigma_{\theta \theta}(\theta=0, r=L / 2)=\sigma_{0}
$$

For PM, two conditions characterize fracture onset, i.e., (1) the notch stress intensity factor reaches a critical value, i.e., $K_{I}^{U, \rho}=K_{I c}^{U, \rho}$, and (2) $\sigma_{\text {eff }}=\sigma_{0}$ at $r=\rho / 2+L / 2$ given the coordinate system adopted. On the basis of these two conditions, we can rewrite Equation 1 as Equation 4.

$$
K_{c}^{\text {theor. }}=\frac{\sqrt{\pi(\rho+L)} \sigma_{0}}{1+\rho /(\rho+L)}
$$

In Equation $4, K_{c}^{\text {theor. }}$ is the theoretical prediction of the stress intensity factor during crack onset as a function of root radius $\rho$, characteristic length $L$, and inherent strength $\sigma_{0}$.

In the case of LM, the effective stress is determined by averaging the linear-elastic stresses over a line ahead of the notch tip. Failure occurs when the effective stress $\sigma_{\text {eff }}$ exceeds the inherent strength of the material $\sigma_{0}$ at a distance $2 L$ from the tip (Figure 2b). Equation 5 expresses the mathematical formalization of $\mathrm{LM}^{12}$.

$$
\sigma_{e f f}=\frac{1}{2 L} \int_{0}^{2 L} \sigma(\theta=0, r) d r=\sigma_{0}
$$

Given that Equation 1 expresses the stress field as $\sigma(\theta=0, r)$, Equation 5 can be integrated from $-\rho / 2$ to $(\rho / 2+2 L)$, resulting in Equation 6 after extracting the stress intensity factor.

$$
K_{c}^{\text {theor. }}=\frac{2 \sqrt{2 \pi} \sigma_{0} L}{2 \sqrt{\rho / 2+2 L}-\frac{\rho}{\sqrt{\frac{\rho}{2}+2 L}}}
$$

Similar to PM, $K_{c}^{\text {theor. }}$ is the theoretical prediction of the stress intensity factor during crack onset as a function of root radius $\rho$, characteristic length $L$, and inherent strength $\sigma_{0}$.

\subsection{Characteristic length and inherent strength}

In previous studies, Whitney and Nuismer ${ }^{5}$ stated that the same value of characteristic length $L$ yielded good fitting for both conditions evaluated, i.e., circular holes in quasiisotropic glass/epoxy and straight cracks in graphite/epoxy, with the specimens having different laminated constructions. At that moment, they determined that $L$ could be constant for various laminates, geometric discontinuities, and material systems. After considerable research, current results indicate that characteristic length varies with the material and failure processes. $L$ is usually associated with the material microstructural features, such as grain size, as observed in cases of brittle fracture in engineering ceramics and steel ${ }^{7}$.

With regard to inherent strength $\sigma_{0}$, precise estimates and its meaning, particularly when working with metallic materials, need to be obtained. Indeed, for ceramics and composite materials, many studies ${ }^{2,10}$ support the finding that inherent strength $\sigma_{0}$ is equal to ultimate tensile strength $\sigma_{u, t}$. This assumption is valid for classic brittle and quasi-brittle materials, which exhibit small-scale plastic deformation before failure. Conversely, for materials that exhibit medium-scale or large-scale plastic deformation, ultimate tensile strength does not represent a good estimate of inherent strength. This finding is true for metallic materials and certain groups of polymers. For these materials, $\sigma_{0}$ usually reaches values up to 10 times greater than $\sigma_{\mathrm{u}, \mathrm{t}}{ }^{7}$.

Theoretical background indicates that inherent strength $\sigma_{0}$ has no physical meaning because it is an elasticity-based parameter in a region where actual stresses are gradually modified by plasticity, general damage, and several nonlinear phenomena. Indeed, a better comprehension of the meaning of $\sigma_{0}$ is necessary, although current studies confirm that, for materials that exhibit extensive plasticity before failure, $\sigma_{0}$ reaches values significantly greater than $\sigma_{u, t^{\circ}}$

Despite the lack of a more precise understanding of $L$ and $\sigma_{0}$, researchers believe that the most accurate technique for determining these properties is testing specimens of the same material with at least two different geometric features and analyzing the stress fields during crack onset ${ }^{12,13}$. The following steps summarize how $L$ and $\sigma_{0}$ are obtained using PM:

1. The test specimens are prepared with different sharpness, i.e., one sharp and the other blunt.

2. Finite element models of the tested specimens are built and failure loads are applied to analyze the stress field ahead of the notch tip.

3. Stress field curves related to each notch type are plotted in the same graph and the point where the curves intersect is identified. According to the mathematical formalization of PM, this point represents $L / 2$ and $\sigma_{0}$. 


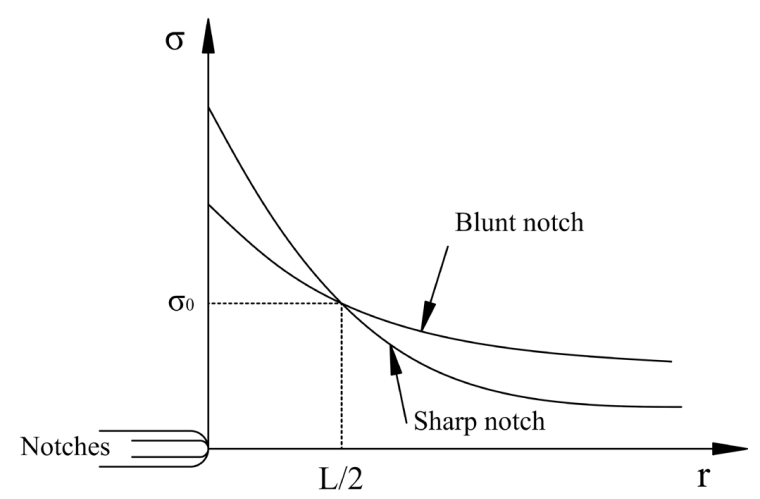

Figure 3. Linear-elastic stress versus distance curve for notches with different features.

Figure 3 depicts the procedure. For LM, the procedure is complex and requires the calculation of the area under the stress field curves (Equation 5) to determine the value of $r$, for which the area of both curves present the same value. The value of $r$ represents $2 L$ according to LM.

\section{Calculation Procedures}

\subsection{Failure criteria evaluation}

In this study, the capability of the considered methods to predict failure will be assessed by comparing the theoretical stress intensity factor with the experimental stress intensity factor.

The theoretical stress intensity factor $K_{c}^{\text {theor. }}$ will be determined using Equation 4 or 6 according to PM or LM, respectively. First, $\sigma_{u, t}$ will be considered an initial estimate of $\sigma_{0}$, whereas $L$ will be calculated according to Equation 2, which defines $L$ uniquely as a function of fracture toughness and ultimate tensile strength, i.e., material's properties. Afterward, $L$ and $\sigma_{0}$ will be directly obtained from the plotted curves by linear-elastic stress field analysis, as illustrated in Figure 3. In this case, the material's properties are unnecessary.

The experimental stress intensity factor $K_{c}^{\text {exp. }}$ will be computed using Equation 1 given that the stress $\sigma_{\theta \theta}$ developed at the notch tip $(r=\rho / 2)$ during crack onset. To obtain the value of $\sigma_{\theta \theta}$, the failure loads of the tested specimens will be applied in the finite element models.

Equation 7 expresses the error considered for the desired comparison.

$$
\operatorname{Error}[\%]=\frac{K_{c}^{\text {exp. }}-K_{c}^{\text {theor. }}}{K_{c}^{\text {theor. }}}
$$

\subsection{Failure assessment of V-notched specimens}

As previously mentioned, the values of $\sigma_{0}$ and $L$ that successfully estimated the failure of U-notched bending specimens will be used to evaluate the failure of uniaxially loaded V-notched rounded specimens machined with the same AISI 420. Papers in the literature show that, for the same material with the same thermal treatment history, $\sigma_{0}$ and $L$ can be applied to failure prediction, regardless of the loading mode and specimen geometry ${ }^{8,13}$.
Ayatollahi and Torabi ${ }^{19}$ investigated brittle fracture in rounded-tip V-notched specimens loaded under three-point and four-point bending. Meanwhile, Torabi ${ }^{20}$ evaluated the loadbearing capacity of bolts with V-shaped threads. Both works used the analytical approach proposed by Filippi et al. ${ }^{21}$ for describing the local stress field ahead of rounded-tip V-notched specimens and obtained good predictions. In the present work, the theoretical stress intensity factor for LM and PM will be calculated according to the formulas present in the aforementioned studies.

Meanwhile, the experimental stress intensity factor will be computed as the mean value (from the notch tip up to a distance equal to $\eta \rho$, where $\eta=0.4$ ) to eliminate the weak dependence on the notch tip distance. Lazzarin and Filippi ${ }^{22}$ proposed this correction because of the oscillating values observed for the stress intensity factor ahead of the notch tip as a consequence of the approximate analytical solution for blunted $\mathrm{V}$-notches given that it satisfies the boundary conditions only at the notch tip and at a certain distance from it.

For the sake of simplicity, equations involved in V-notch failure assessment are not discussed here but can be found in articles in the literature ${ }^{19-22}$.

\section{Materials and Methods}

Table 1 presents the chemical composition of AISI 420 used in this study, determined using the SpectroMaxx optical emission spectrometer. The values obtained are consistent with the ASTM A240-17 standard specification for AISI 420.

AISI 420 was supplied as a hot-rolled plate with thickness of $16 \mathrm{~mm}$ in the annealed condition. Plates were cut out and machined into specimens for the tensile, toughness, and four-point bending tests. All specimens were machined with the largest dimension parallel to the rolling direction of the purchased plate. For notched specimens, this means that the notch opening direction was parallel to rolling direction.

Tensile tests were performed according to the ASTM E816 standard specification ${ }^{23}$ using small-size specimens with rounded section and the following dimensions: overall length $100 \mathrm{~mm}$, length of reduced section $36 \mathrm{~mm}$, and diameter of reduced section $6 \mathrm{~mm}$. Tests for the determination of fracture toughness $K_{\text {Ic }}$ were performed according to the ASTM E39917 standard specification ${ }^{24}$ using compact tensile specimens C(T) with $W=25.4 \mathrm{~mm}$ and $B=12.7 \mathrm{~mm}$.

Specimens used in the four-point bending test were machined with the length of $130 \mathrm{~mm}$ and two different sections, i.e., $14 \mathrm{~mm} \times 14 \mathrm{~mm}$ and $14 \mathrm{~mm} \times 7 \mathrm{~mm}$. U-notches with the radii of 0.17 and $1 \mathrm{~mm}$ were prepared using electroerosion as well as $\mathrm{V}$-notches with the radii $0.17 \mathrm{~mm}$ and $60^{\circ}$ opening. In the four-point bending tests, load and support spans of 50 and $100 \mathrm{~mm}$ were used, respectively.

V-notched specimens with circular cross-section and loaded under tensile stress were machined from the same plate of bending specimens, respecting also the same rolling orientation.

Figure 4 depicts general dimensions of the notched specimens which are summarized in Table 2, including the number of tested specimens. 
Table 1. Chemical composition of the purchased AISI 420 (in wt $\%$ ).

\begin{tabular}{cccccccccc}
\hline $\mathrm{Fe}$ & $\mathrm{C}$ & $\mathrm{Cr}$ & $\mathrm{Mn}$ & $\mathrm{P}$ & $\mathrm{S}$ & $\mathrm{Si}$ & $\mathrm{Ni}$ & $\mathrm{Mo}$ \\
\hline 85.7 & 0.367 & 12.790 & 0.459 & 0.013 & $<0.001$ & 0.349 & 0.126 & 0.013 \\
\hline $\mathrm{V}$ & $\mathrm{Nb}$ & $\mathrm{Cu}$ & $\mathrm{Al}$ & $\mathrm{Co}$ & $\mathrm{Pb}$ & $\mathrm{Sn}$ & $\mathrm{W}$ & \\
\hline 0.067 & 0.027 & 0.020 & 0.019 & 0.014 & $<0.03$ & $<0.01$ & $<0.01$ & \\
\hline
\end{tabular}

Table 2. General dimensions of the tested specimens.

\begin{tabular}{|c|c|c|c|}
\hline \multicolumn{4}{|c|}{ U-NOTCHED PLATE } \\
\hline $\begin{array}{l}\text { Thickness } t \\
\text { (mm) }\end{array}$ & $\begin{array}{l}\text { Notch Tip } \\
\text { Radius } \rho \\
(\mathrm{mm})\end{array}$ & $\begin{array}{l}\text { Notch Depth } d \\
\quad(\mathrm{~mm})\end{array}$ & $\begin{array}{c}\text { Number of } \\
\text { Tested Specimens }\end{array}$ \\
\hline \multirow{2}{*}{7} & 0.17 & \multirow{4}{*}{5} & 5 \\
\hline & 1 & & 5 \\
\hline \multirow{2}{*}{14} & 0.17 & & 4 \\
\hline & 1 & & 5 \\
\hline \multicolumn{4}{|c|}{ V-NOTCHED PLATE $\left(60^{\circ}\right)$} \\
\hline $\begin{array}{l}\text { Thickness } t \\
\text { (mm) }\end{array}$ & $\begin{array}{c}\text { Notch Tip } \\
\text { Radius } \rho \\
(\mathrm{mm}) \\
\end{array}$ & $\begin{array}{l}\text { Notch Depth } d \\
\quad(\mathrm{~mm})\end{array}$ & $\begin{array}{c}\text { Number of } \\
\text { Tested Specimens }\end{array}$ \\
\hline 7 & \multirow{2}{*}{0.17} & \multirow{2}{*}{5} & 5 \\
\hline 14 & & & 5 \\
\hline \multicolumn{4}{|c|}{ V-NOTCHED ROUNDED BAR } \\
\hline Angle $(2 \alpha)$ & $\begin{array}{l}\text { Notch Tip } \\
\text { Radius } \rho \\
(\mathrm{mm})\end{array}$ & $\begin{array}{l}\text { Ligament } b \\
\quad(\mathrm{~mm})\end{array}$ & $\begin{array}{c}\text { Number of } \\
\text { Tested Specimens }\end{array}$ \\
\hline $60^{\circ}$ & 0.39 & 3.08 & 4 \\
\hline $90^{\circ}$ & 0.59 & 3.68 & 3 \\
\hline
\end{tabular}
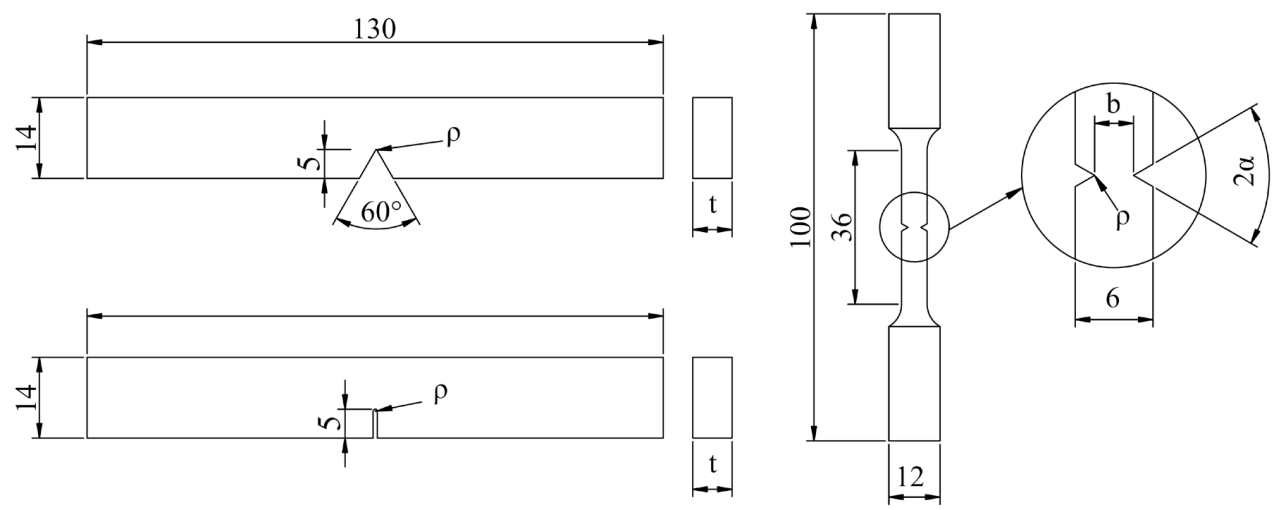

Figure 4. Geometry of specimens tested specimens (dimensions in millimeters).

Table 3. Parameters for stress intensity factor $-\mathrm{V}$-notched.

\begin{tabular}{ccccccccccc}
\hline \multicolumn{10}{c}{ V-NOTCHED PLATE $\left(60^{\circ}\right)$} \\
\hline Angle $(2 \alpha)$ & Tip Radius $\rho(\mathrm{mm})$ & $q$ & $r_{0}(\mathrm{~mm})$ & $\lambda_{1}$ & $\mu_{1}$ & $\chi_{\mathrm{b} 1}$ & $\chi_{\mathrm{c} 1}$ & $\chi_{\mathrm{d} 1}$ & $\omega_{1}$ & $\eta_{\theta \theta}(0)$ \\
\hline $60^{\circ}$ & 0.17 & 1,667 & 0.068 & 0.512 & -0.406 & 1.312 & 3.283 & 0.096 & 0.970 & 0.970 \\
\hline \multicolumn{7}{c}{ V-NOTCHED ROUNDED BAR } \\
\hline Angle $(2 \alpha)$ & Tip Radius $\rho(\mathrm{mm})$ & $q$ & $r_{0}(\mathrm{~mm})$ & $\lambda_{1}$ & $\mu_{1}$ & $\chi_{\mathrm{b} 1}$ & $\chi_{\mathrm{c} 1}$ & $\chi_{\mathrm{d} 1}$ & $\omega_{1}$ & $\eta_{\theta \theta}(0)$ \\
\hline $60^{\circ}$ & 0.39 & 1.667 & 0.156 & 0.512 & -0.406 & 1.312 & 3.283 & 0.096 & 0.970 & 0.969 \\
\hline $90^{\circ}$ & 0.59 & 1.500 & 0.196 & 0.545 & -0.345 & 1.841 & 2.506 & 0.105 & 0.810 & 0.810 \\
\hline
\end{tabular}

Table 3 presents the parameters necessary to compute the stress intensity factor for $\mathrm{V}$-notched specimens ${ }^{22}$.

After machining, the specimens were preheated at $600^{\circ} \mathrm{C}$ for $15 \mathrm{~min}$ and austenitized at $1,150^{\circ} \mathrm{C}$ for $30 \mathrm{~min}$. Afterward, the specimens were oil quenched and then tempered at $390^{\circ} \mathrm{C}$ for $30 \mathrm{~min}$, followed by furnace cooling. Austenitization was performed in a neutral salt bath to prevent decarburization ${ }^{16}$. Heating rates were established at $0.35^{\circ} \mathrm{C} / \mathrm{min}$. 
The specimens were machined before heat treatment, except the notches, which were generated afterward to prevent distortion and microcrack development due to thermal stresses.

The Rockwell C hardness (HRC) of the specimens was evaluated using the Panambra Pantec RBS durometer. Measurements were performed with $150 \mathrm{kgf}$ of applied load during 6 s over polished specimens.

Finite element analysis (FEA) was conducted using the commercial software Ansys. Linear-elastic models were prepared and a plane stress state was considered. Elements around the notch tip were properly refined because it was necessary to obtain a stress versus distance curve that departs from the notch apex with small increments. In this area, an element size of $2 \mu \mathrm{m}$ was employed.

Accurate measurements of the radii of the notches and the general features of fractured specimens were also performed using the Olympus LEXT OLS4000 3D confocal laser microscope.

Samples for microstructural characterization were grited with abrasive silicon carbide waterproof paper up to 1200 grit and polished with alumina powder with the particle size of $1 \mu \mathrm{m}$ in water suspension. Afterward, the samples were etched electrolytically with $10 \mathrm{wt} \%$ oxalic acid. To ensure better comprehension of the microstructure of the samples, after obtaining the images, the samples were once more grited, polished, and etched with Vilella's reagent $(1 \mathrm{~g}$ of picric acid, $5 \mathrm{~mL}$ of $\mathrm{HCl}$, and $95 \mathrm{~mL}$ of ethyl alcohol).

Scanning electron microscopy images were obtained using the Shimadzu SuperScan SSX-550 for microstructural characterization and fractographic analysis.

\section{Results and Discussion}

\subsection{Microstructural characterization}

Figures 5 shows the microstructure of the samples obtained with backscattered electrons. Aligned carbides identified in the images are the result of the hot rolling process, characterizing the carbide banding phenomenon ${ }^{25}$. As a result of growth and coalescence during the hot rolling process, some carbide particles have a larger dimension than other particles. A banded microstructure is characterized by dark/light bands, resulting in the variations in the carbide size and density, called carbide density banding ${ }^{26}$. Usually, a banded microstructure is described as a segregated structure with two different phases aligned approximately parallel with the working direction ${ }^{25}$.

Heat treatment resulted in a microstructure that consists of a tempered martensite matrix with undissolved carbides dispersed, as shown in Figure 6.

The microstructure of AISI 420 stainless steel after quenching and tempering is usually characterized by the presence of carbides, tempered martensite and eventually retained austenite, although martensite can persist in tempering temperature ${ }^{14,15}$. Depending on the austenitizing temperature, $\delta$-ferrite may also be present ${ }^{27,28}$. Large carbides are associated with $\mathrm{M}_{7} \mathrm{C}_{3}$, whereas small carbides are associated with $\mathrm{M}_{23} \mathrm{C}_{6}^{29}$.

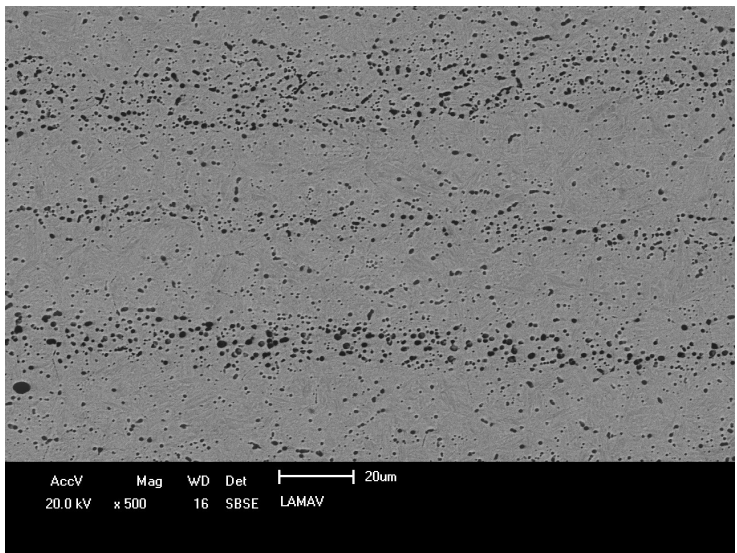

Figure 5. Microstructure of AISI 420 etched with $10 \mathrm{wt} \%$ oxalic acid.

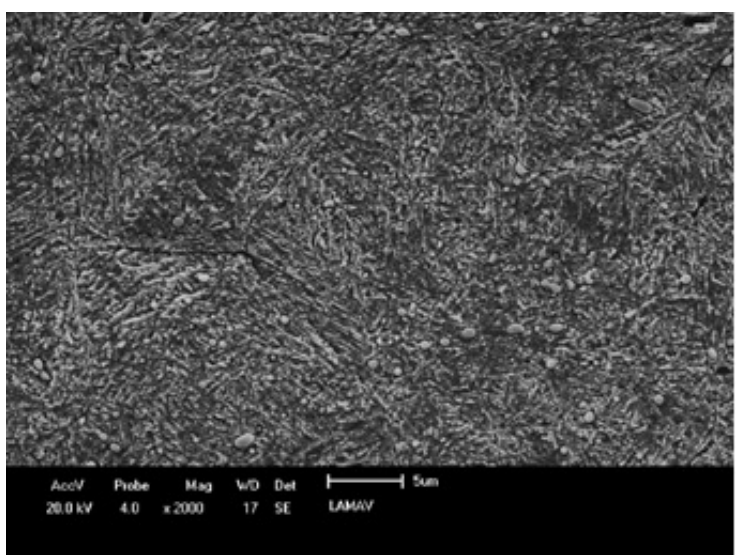

Figure 6. Microstructure of AISI 420 etched with Vilella's reagent.

Table 4. Mechanical properties of the tested AISI 420.

\begin{tabular}{cccc}
\hline$\sigma_{\mathrm{y}}$ & Yield strength & 1159 & $\mathrm{MPa}$ \\
\hline$E$ & Young's modulus & 197228 & $\mathrm{MPa}$ \\
\hline$\sigma_{\mathrm{u}, \mathrm{t}}$ & $\begin{array}{c}\text { Ultimate tensile strength } \\
\text { true value }\end{array}$ & 1796 & $\mathrm{MPa}$ \\
\hline$\varepsilon_{\mathrm{u}, \mathrm{t}}$ & True strain at rupture & 0.0386 & $\mathrm{~mm} / \mathrm{mm}$ \\
\hline $\mathrm{AR} \%$ & Area reduction & $5.60 \%$ & \\
\hline$n$ & Strain hardening exponent & 0.160 & $\mathrm{MPa}$ \\
\hline$K$ & Strain hardening coefficient & 3156.6 & $\mathrm{MPa} \sqrt{\mathrm{m}}$ \\
\hline$K_{\mathrm{Ic}}$ & Plane strain fracture \\
toughness & 35.4 & $\mathrm{HRC}$ \\
\hline
\end{tabular}

\subsection{Mechanical properties}

Table 4 presents the mechanical properties of AISI 420. For the tensile tests, five specimens were tested. Tensile specimens exhibited small necking after rupture, with a full flat fracture surface. Figure 7 shows the engineering stress-strain curves of the tested specimens.

For the determination of plane strain fracture toughness $K_{\text {Ic }}$, three specimens yielded valid values according to the ASTM E399-1721 standard specification. Strain hardening exponent $n$ and strain hardening coefficient $K$ were obtained 


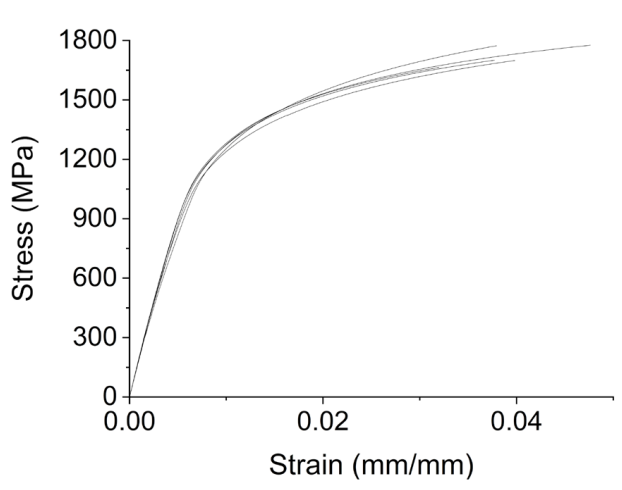

Figure 7. Engineering stress-strain curves of the tested specimens.

using Method A of the ASTM E646-16 standard specification ${ }^{30}$. The values listed in Table 4 are the average values of the individual tests performed.

\subsection{Four-point bending test}

Table 5 lists the average values of the load-bearing capacity of the tested specimens according to the specimen's thickness and notch tip radius $\rho$. The dispersion of the results was considered to be small. The highest value of the coefficient of variation was $7.6 \%$ for specimens with the thickness of $7 \mathrm{~mm}$ and $\rho=0.17 \mathrm{~mm}$, whereas the lowest value of the coefficient of variation was $2.0 \%$ for specimens with the thickness of $7 \mathrm{~mm}$ and $\rho=1 \mathrm{~mm}$. The coefficient of variation $(\mathrm{COV})$ is defined as the ratio of the standard deviation to the mean.

The four-point bending results for U-notched specimens (Table 5) indicate the linear behavior of the load-bearing capacity relative to the thickness because specimens with the thickness of $14 \mathrm{~mm}$ require two times more force to reach failure than specimens with the thickness of $7 \mathrm{~mm}$, regardless of the notch tip radius. Similarly, the increase in thickness does not affect the stress concentration factor defined by the notch tip radius: rupture of specimens with the radius of $0.17 \mathrm{~mm}$ occurs with approximately $63 \%$ of the load necessary to break specimens with the radius of $1 \mathrm{~mm}$, regardless of the thickness. These considerations indicate that both thicknesses investigated are under the same stress state.

The region around the notch tip of four-point bending specimens was checked with a confocal laser microscope before and after testing. Checking the notch tip before testing aimed to verify the presence of microcracks and small damages eventually generated during machining and/ or heat treatment. Meanwhile, verification after fracture confirms if cracking started at or close to the notch tip apex. The theoretical approach considered in this work ${ }^{18}$ states that elastic stress in the bisector reaches its maximum value at the notch tip apex. Therefore, if cracking initiates in other locations, then something went wrong, e.g., specific damage near the notch tip, localized microstructural differences or specimens were placed incorrectly in the testing machine (misalignment) which could result in unsymmetrical loading and differential stresses.

Verification before testing revealed minor scratches and irregularities characteristic of machining and electro-erosion
Table 5. Average load-bearing capacity of the tested specimens.

\begin{tabular}{ccccc}
\hline \multicolumn{5}{c}{ U-NOTCHED PLATE } \\
\hline Thickness $(\mathrm{mm})$ & $\rho=1 \mathrm{~mm}$ & COV & $\rho=0.17 \mathrm{~mm}$ & COV \\
\hline 7 & $23221 \mathrm{~N}$ & $2.0 \%$ & $14819 \mathrm{~N}$ & $7.6 \%$ \\
\hline 14 & $46921 \mathrm{~N}$ & $5.0 \%$ & $29604 \mathrm{~N}$ & $2.7 \%$ \\
\hline \multicolumn{5}{c}{ V-NOTCHED PLATE $\left(60^{\circ}\right)$} \\
\hline Thickness (mm) & $\rho=0.17 \mathrm{~mm}$ & COV \\
\hline 7 & $15547 \mathrm{~N}$ & $12.6 \%$ \\
\hline 14 & $32642 \mathrm{~N}$ \\
\hline \multicolumn{5}{c}{$7.6 \%$} \\
\hline Angle $(2 \alpha)$ & V-NOTCHED ROUNDED BAR \\
\hline $60^{\circ}$ & $0.39 \mathrm{~mm}$ & COV \\
\hline $90^{\circ}$ & $0.59 \mathrm{~mm}$ & $20559 \mathrm{~N}$ & $8.6 \%$ \\
\hline \multicolumn{4}{c}{$26998 \mathrm{~N}$} \\
\hline
\end{tabular}

but no relevant damage. Verification after testing invalidated two tests, indicating misaligned specimens.

Observation of the specimens after rupture also revealed that loading stimulated the occurrence of several microcracks, as shown in Figure 8. Figure 8a shows two halves of a fractured specimen placed side by side with the crack in the middle of the image. Crack onset is located at the notch apex. Figure $8 \mathrm{~b}$ shows the sideline of the notch. Both images show that microcracks depart from the notch edge and are orientated perpendicular to the curvature radius. Progressively, microcracks change direction and become perpendicular to the principal stress direction. Figure 8c shows the sketch of specific regions observed in the bending specimens.

Microcracks were observed in all of the tested specimens under four-point bending, without relevant differences. Analysis of different specimens indicates that thickness does not affect microcrack appearance, unlike the notch tip radius. Notch tips with the radius of $0.17 \mathrm{~mm}$ lead to a high density of microcracks around the notch, whereas notch tips with the radius of $1 \mathrm{~mm}$ generate cracks with a large aperture.

\subsection{Fracture appearance}

Figure 9 shows the fracture surfaces of four tested specimens. In each image, both sides of a broken specimen placed side by side are shown. The fracture appearance is typical of brittle fracture.

Figure 10 shows the image of the fractured surface obtained using a scanning electron microscope with a magnification of $50 \times$. The borderline between the end of the notch and the beginning of the cracked surface, as well as the cracking direction, is illustrated. In this image, a fracture typical of brittle mechanism can be identified. Indeed, during the fourpoint bending test, rupture of specimens occurred suddenly, without visible crack growth or plastic deformation.

A detailed examination of two selected regions of the fracture, i.e., one near the notch tip (approximately $175 \mu \mathrm{m}$ ) and the other far from the notch tip (approximately near the fracture surface center), was conducted. To ensure better comprehension, the length corresponding to $175 \mu \mathrm{m}$ is marked in Figure 10. Figure 11 depicts the general features of the regions observed.

Although macroscopic evaluation of the fracture surface of bending specimens indicates brittle fracture (Figure 9), microscopic analysis allows additional considerations. Figure 11a shows the fracture surface in region near the crack 

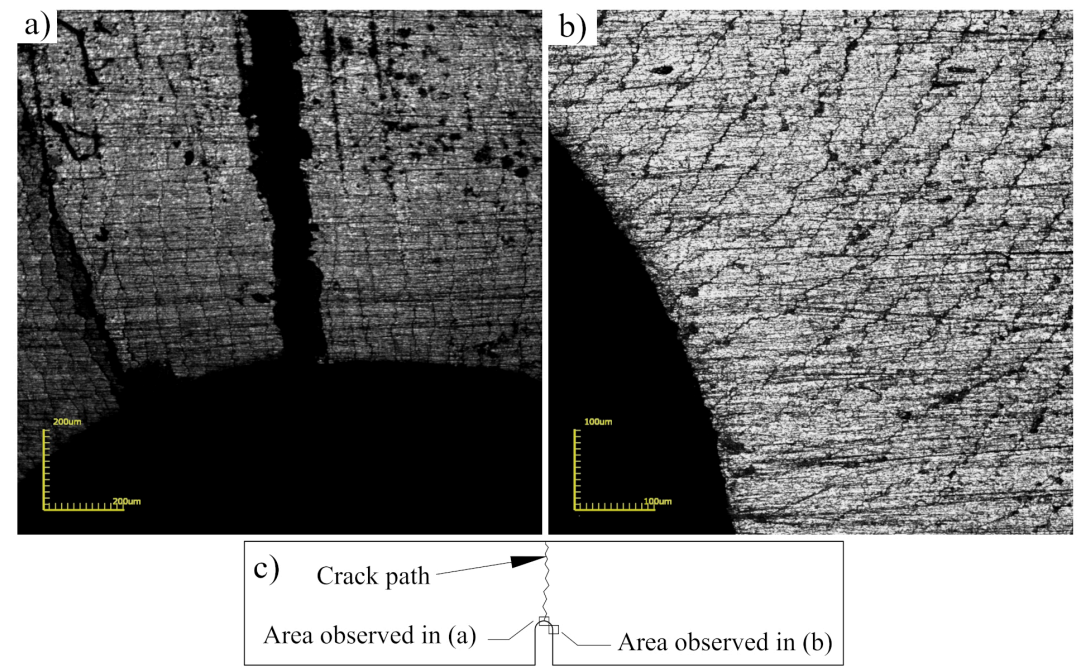

Figure 8. Microcracks in the region around the notch tip of the specimen with the thickness of $7 \mathrm{~mm}$ and notch tip radius of $1 \mathrm{~mm}$ : (a) notch tip apex, 216×; (b) notch tip sideline, 430×; (c) sketch indicating the observed regions.
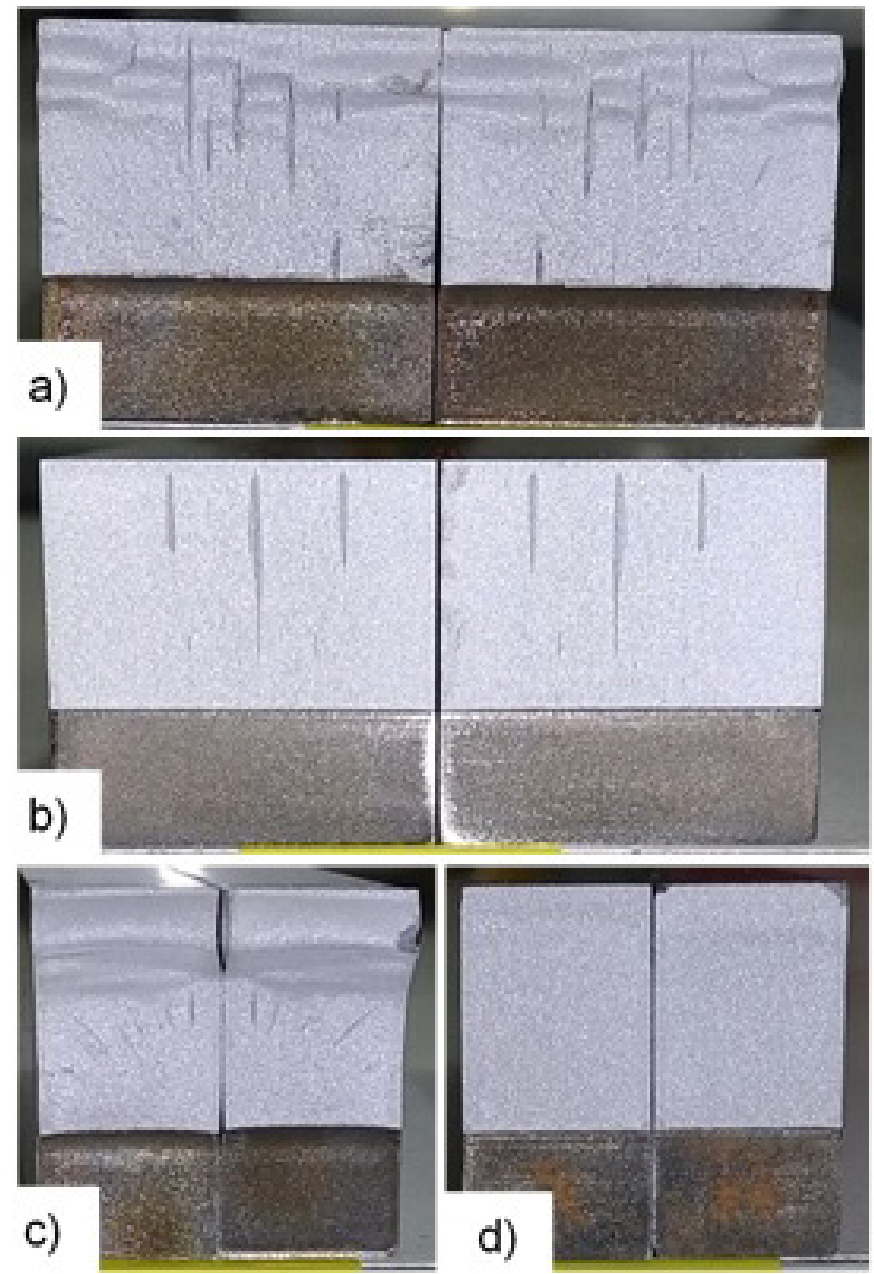

Figure 9. Fracture surface: (a) thickness of $14 \mathrm{~mm}$ and radius of $1 \mathrm{~mm}$, (b) thickness of $14 \mathrm{~mm}$ and radius of $0.17 \mathrm{~mm}$, (c) thickness of $7 \mathrm{~mm}$ and radius of $1 \mathrm{~mm}$, and (d) thickness of $7 \mathrm{~mm}$ and radius of $0.17 \mathrm{~mm}$. 
tip, while Figure 11 b presents a region away from crack tip. In both studied regions, a predominance of microvoids is observed where dimples can be distinguished. This examination indicates that the fracture results of microvoid coalescence can be characterized as a fully ductile fracture.

The fracture analysis results are consistent with the tensile test results. A small area reduction (5.6\%) is observed, although the engineering stress-strain curve behavior indicates the occurrence of yielding. In this case, yielding occurs as a result

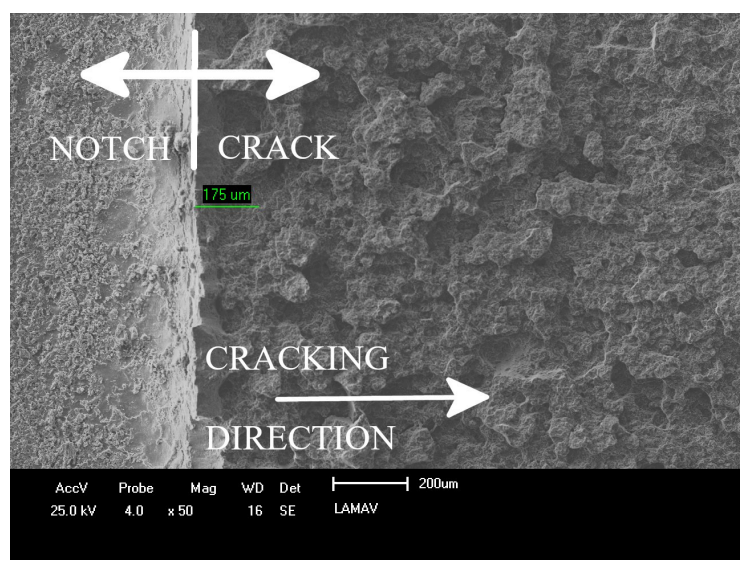

Figure 10. Fracture surface observed using a scanning electron microscope with a low magnification $(50 \times)$.
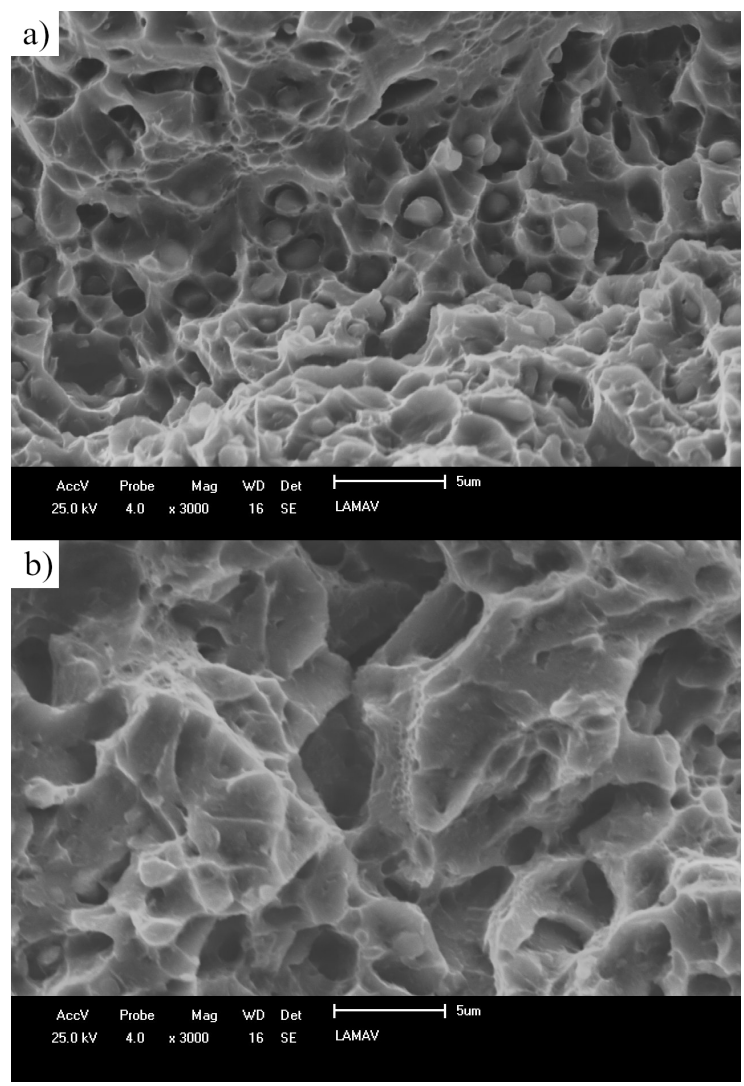

Figure 11. Scanning electron microscopy images of the fracture surface near (a) and far (b) from the notch tip in two different specimens (magnification of $3000 \times$ ). of localized plasticity around the rupture region. Thus, the material can be characterized as exhibiting small-scale yielding.

\subsection{Failure criteria application}

Table 6 shows the theoretical predictions of the stress intensity factor according to Equations 4 and 6 for PM and LM, respectively. In this case, characteristic length $L$ was computed according to Equation 2, using $K_{\mathrm{Ic}}$ obtained on the basis of the ASTM E399-17 standard specification and considering ultimate tensile strength $\sigma_{\mathrm{u}, \mathrm{t}}$ of the material as an initial estimate for $\sigma_{0}$.

The average values of the failure loads determined in the four-point bending test (Table 5) were applied in the finite element models to determine the critical stress at the notch tip, which is considered the stress during crack onset. Then, the stresses obtained were applied in Equation 1, resulting in the experimental stress intensity factors $K_{c}^{\exp }$. for each thickness and notch tip radius, as presented in Table 7.

Table 8 shows the errors according to the specimen's thickness and notch tip radius calculated using Equation 7.

Table 6. Theoretical predictions of $K_{\mathrm{c}}^{\text {theor. }}(\mathrm{MPa} \sqrt{\mathrm{m}})$ for the tested specimens under bending loading.

\begin{tabular}{ccc}
\hline \multicolumn{3}{c}{ ACCORDING TO THE EQUATION 2 } \\
\hline \multicolumn{3}{c}{ METHOD } \\
\hline Tip radius & PM & LM \\
\hline $1 \mathrm{~mm}$ & 56.5 & 61.5 \\
\hline $0.17 \mathrm{~mm}$ & 34.5 & 41.0 \\
\hline \multicolumn{3}{c}{ METHOD } \\
\hline ACCORDING TO THE GRAPHICAL ANALYSIS \\
\hline Thickness $\mid$ Tip radius & PM & LM \\
\hline$t=7 \mathrm{~mm} \mid \rho=1 \mathrm{~mm}$ & 185.2 & 184.8 \\
\hline$t=7 \mathrm{~mm} \mid \rho=0.17 \mathrm{~mm}$ & 112.0 & 112.5 \\
\hline$t=14 \mathrm{~mm} \mid \rho=1 \mathrm{~mm}$ & 187.4 & 186.8 \\
\hline$t=14 \mathrm{~mm} \mid \rho=0.17 \mathrm{~mm}$ & 112.1 & 112.8 \\
\hline
\end{tabular}

Table 7. Experimental values of $K^{\exp }(\mathrm{MPa} \sqrt{\mathrm{m}})$ for U-notched specimens.

\begin{tabular}{ccc}
\hline \multirow{2}{*}{ Tip radius } & \multicolumn{2}{c}{ Specimen Thickness } \\
\cline { 2 - 3 } & $7 \mathrm{~mm}$ & $14 \mathrm{~mm}$ \\
\hline$\rho=1 \mathrm{~mm}$ & 186.2 & 188.1 \\
\hline$\rho=0.17 \mathrm{~mm}$ & 112.7 & 112.7 \\
\hline
\end{tabular}

Table 8. Percentage error for U-notched stress intensity factor prediction.

\begin{tabular}{ccc}
\hline \multicolumn{3}{c}{ ACCORDING TO THE EQUATION 2 } \\
\hline & \multicolumn{2}{c}{ ERROR } \\
\hline Thickness $\mid$ Tip radius & PM & LM \\
\hline$t=7 \mathrm{~mm} \mid \rho=1 \mathrm{~mm}$ & $229.8 \%$ & $202.7 \%$ \\
\hline$t=7 \mathrm{~mm} \mid \rho=0.17 \mathrm{~mm}$ & $226.4 \%$ & $174.8 \%$ \\
\hline$t=14 \mathrm{~mm} \mid \rho=1 \mathrm{~mm}$ & $233.2 \%$ & $205.8 \%$ \\
\hline$t=14 \mathrm{~mm} \mid \rho=0.17 \mathrm{~mm}$ & $226.5 \%$ & $174.9 \%$ \\
\hline ACCORDING TO THE GRAPHICAL ANALYSIS \\
\hline \multicolumn{3}{c}{ ERROR } \\
\hline \multicolumn{3}{c}{ PM } \\
\hline Thickness $\mid$ Tip radius & $0.54 \%$ & $0.77 \%$ \\
\hline$t=7 \mathrm{~mm} \mid \rho=1 \mathrm{~mm}$ & $0.63 \%$ & $0.17 \%$ \\
\hline$t=7 \mathrm{~mm} \mid \rho=0.17 \mathrm{~mm}$ & $0.34 \%$ & $0.72 \%$ \\
\hline$t=14 \mathrm{~mm} \mid \rho=1 \mathrm{~mm}$ & $0.58 \%$ & $-0.04 \%$ \\
\hline$t=14 \mathrm{~mm} \mid \rho=0.17 \mathrm{~mm}$
\end{tabular}


The high values strongly indicate that ultimate tensile strength $\sigma_{u, t}$ does not represent a good estimate of inherent strength $\sigma_{0}$. This is probably related to localized plastic deformation around the notch tip and extensive presence of microcracks detected in bending specimens after failure (Figure 8). The cracking phenomenon promotes energy dissipation as a consequence of localized plastic deformation around the crack front and generation of free surfaces ${ }^{31}$. Therefore, countless microcracks detected in bending specimens served as energy-dissipating elements in such a way that high loads were necessary to reach a critical value of the stress intensity factor and promote failure. Indeed, for brittle and quasi-brittle materials, microcrack development can be considered a toughening mechanism.

As previously explained, several authors have stated that the most accurate way to determine $L$ consists of analyzing the stress field ahead of the notch tip. Thus, Figures 12 and 13 show the stress fields calculated using FEA for PM and LM, respectively.

Figures $12 \mathrm{a}$ and $13 \mathrm{a}$ present the analysis of specimens with the thickness of $7 \mathrm{~mm}$, whereas Figures $12 \mathrm{~b}$ and $13 \mathrm{~b}$ present the analysis of specimens with the thickness of $14 \mathrm{~mm}$. The values obtained for $L$ and $\sigma_{0}$ for each method and thickness are indicated in the same figures.

For PM, in Figure 12, the dashed lines indicate $L$ and $\sigma_{0}$ in the intersection of the stress field curves of specimens with different stress raisers. Given that LM has a different mathematical formalization, in Figure 13, the dashed lines indicate the distance $2 L$ ahead of the notch tip for which

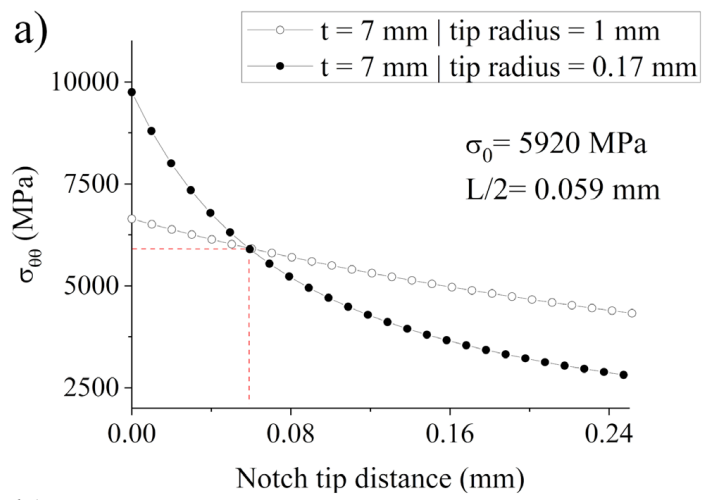

b)

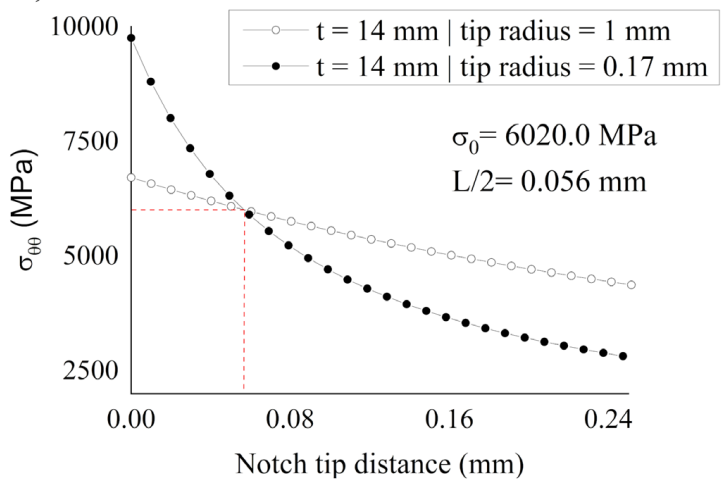

Figure 12. Stress field analysis according to PM: (a) thickness of $7 \mathrm{~mm}$ and (b) thickness of $14 \mathrm{~mm}$. the area under stress field curves reaches the same value. The ratio between this area and $2 L$ yields the $\sigma_{0}$ value. This is the reason why the dashed lines for LM do not lie over any specific point of the curves.

The values for inherent strength $\sigma_{0}$ do not exhibit a significant variation regardless of the method used or specimen thickness. The average value of $5878 \mathrm{MPa}$ is the most representative value.

Conversely, characteristic distance $L$ assumes different values according to the method, i.e., $115 \mu \mathrm{m}$ for PM and $78 \mu \mathrm{m}$ for LM. For the same method, thickness variation from $7 \mathrm{~mm}$ to $14 \mathrm{~mm}$ shows no influence.

Table 6 also shows the theoretical prediction of $K_{c}^{\text {theor. }}$. calculated using $L$ and $\sigma_{0}$ obtained from stress field analysis applied in Equations 4 and 6. Table 8 presents the errors calculated using Equation 7. The percentage errors are lower than $\pm 1 \%$, indicating accurate prediction, which enables a consistent evaluation of the material during crack onset and prediction of failure, without using the mechanical properties previously obtained from standardized tests.

TCD is sensitive to complex phenomena that occur around the notch tip, even when these phenomena are not limited to a small region and microcracks are detected in the specimens investigated. In the present work, despite the small-scale yielding observed, microcracks are distributed over a large area, indicating that the nonlinear zone is large. This issue is remarkable because TCD is based on linearelastic assumptions and, theoretically, does not consider nonlinear effects, such as plasticity and damage, except if

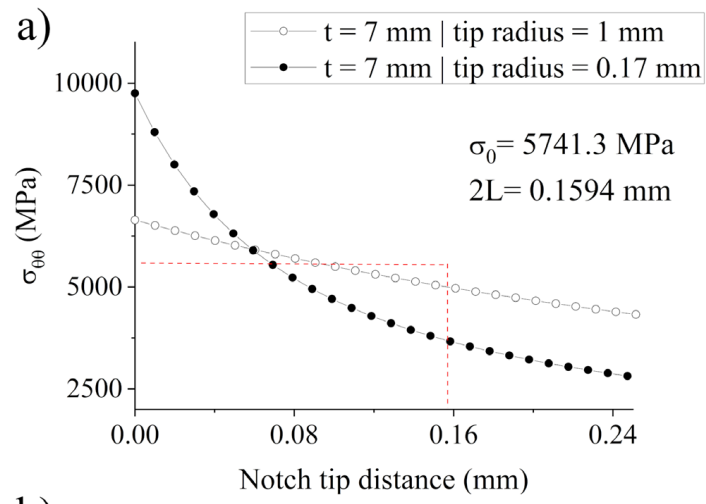

b)

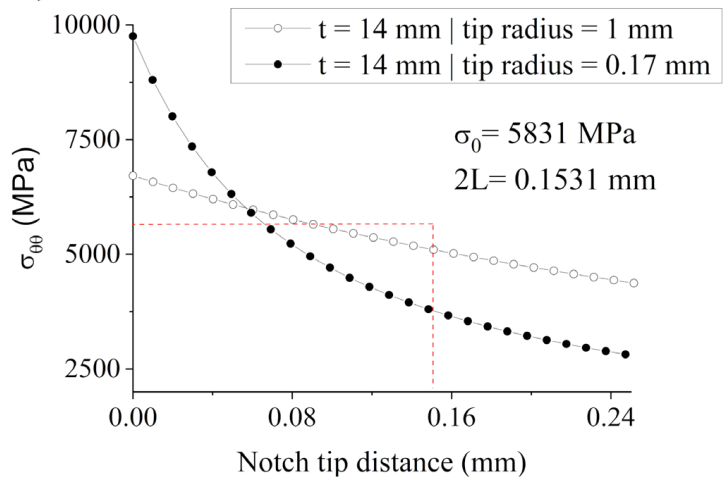

Figure 13. Stress field analysis according to LM: (a) thickness of $7 \mathrm{~mm}$ and (b) thickness of $14 \mathrm{~mm}$. 
the nonlinear zone is limited to a small region compared with the dimension of the body ${ }^{7}$. Creager and Paris's equation also has a linear-elastic framework.

\subsection{Discussing $\sigma_{0}$ and $L$}

The values of $\sigma_{0}$ obtained using stress field analysis and highlighted in Figures 12 and 13 are approximately 3.3 times greater than the ultimate tensile strength $\sigma_{\mathrm{u}, \mathrm{t}}$. Despite $\sigma_{\mathrm{u}, \mathrm{t}}$ usually representing a good estimate for $\sigma_{0}$ when dealing with brittle and quasi-brittle materials, the present material is an exception because of the extensive occurrence of microcracks. The accurate prediction obtained using stress field analysis reinforces the idea that $\sigma_{0}$, despite having no physical meaning, is a suitable representation of local material strength when plastic deformation or damage is not actually modeled ${ }^{12}$. In other words, $\sigma_{0}$ can depict, through linear-elastic representation, nonlinear effects, such as small-scale yielding and widespread microscopic cracking that occur during crack onset.

Table 8 shows that both PM and LM criteria using graphical analysis resulted in accurate predictions of the stress intensity factor during crack onset. Therefore, the criterion that presents the correct value of $L$ needs to be determined. As shown in Figures 12 and 13, the values of 115 and $78 \mu \mathrm{m}$ can be estimated for $L$ using PM and LM, respectively. Reviewing previously published works, Taylor ${ }^{7}$ stated that PM provides better predictions of failure when cleavage is the dominant micro-mechanism, whereas LM has better results for micro-mechanisms involving nucleation and coalescence of microvoids. Conversely, although the tested AISI 420 had presented a fracture resulting to the coalescence of microvoids, similar errors, observed for both methods, did not allow to conclude which one is more appropriate in this case. A comparison between the $L$ estimated and the grain size of the tested material could contribute to this discussion, but the different etching reagents and methodologies applied ${ }^{14,15}$ did not accurately reveal prior austenite grain boundaries, preventing grain size estimate accordingly. Further measurements of the microstructural features are necessary to explore possible correlations with $L$.

\subsection{Evaluation of V-notched specimens}

Thus far, the procedure presented is widely used by several authors to assess the capability of TCD to predict failure. Otherwise, it can be simply considered a calibration procedure; for instance, (1) test specimens with different stress raisers, (2) obtain $L$ and $\sigma_{0}$, (3) calculate the theoretical prediction of $K_{c}$ for the same specimens, (4) calculate the experimental $K_{\mathrm{c}}$ using the failure loads, (5) compute the error, and (6) evaluate the results. When successful, the results indicate that mathematical equations present the appropriate formulation. Thus, in the present work, values of $L$ and $\sigma_{0}$ successfully obtained by testing U-notched plates under bending loading are used to assess the failure of $\mathrm{V}$-notched plates under bending loading and $\mathrm{V}$-notched rounded bars under tensile stress.

Table 5 also shows the average rupture load for $\mathrm{V}$-notched specimens, whereas Table 9 lists the values of the theoretical predictions and experimental results of the stress intensity factor and errors obtained for both V-notched specimens under bending loading (plates) and tensile stress (rounded bar). The stress intensity factor was calculated following the proposed correction of Lazzarin and Filippi ${ }^{22} \cdot K_{c}^{\text {exp. is }}$ the mean value of the stress intensity factor from the notch tip up to a distance equal to $\eta \rho$. Differences in $K_{c}^{\exp .}$ reach $3.66 \%(t=7 \mathrm{~mm})$ and $3.46 \%(t=14 \mathrm{~mm})$ for plates and $4.88 \%\left(2 \alpha=60^{\circ}\right)$ and $5.90 \%\left(2 \alpha=90^{\circ}\right)$ for rounded bars.

With errors up to $9.51 \%$, failure prediction of $\mathrm{V}$-notched specimens was successful, although smaller errors were observed for U-notched specimens, which can be related to mathematical simplifications assumed to calculate the stress intensity factor for $\mathrm{V}$-notches ${ }^{22}$. Table 5 also shows that the increase in thickness from $7 \mathrm{~mm}$ to $14 \mathrm{~mm}$ did not result in a proportional increase in the force necessary to promote failure, i.e., proportionally, specimens with $14 \mathrm{~mm}$ required $5 \%$ more force to fracture, which is probably associated with the variations in the triaxiality degree.

At first glance, failure prediction of V-notched specimens under tensile stress did not show remarkable results, particularly considering that negative error values indicate that failure

Table 9. Assessing V-notched specimen failure.

\begin{tabular}{|c|c|c|c|c|c|}
\hline \multicolumn{6}{|c|}{ V-NOTCHED PLATE $\left(2 \alpha=60^{\circ} ; \rho=0.17 \mathrm{mr}\right)$} \\
\hline \multicolumn{2}{|c|}{ Thickness (mm) } & Method & $K_{\mathrm{c}}^{\text {theor. }}$ & $K_{\mathrm{c}}^{\exp }$ & Error \\
\hline \multirow{2}{*}{\multicolumn{2}{|c|}{7}} & LM & 122.3 & \multirow{2}{*}{122.6} & 0.21 \\
\hline & & PM & 118.5 & & 3.44 \\
\hline \multirow{2}{*}{\multicolumn{2}{|c|}{14}} & LM & 122.4 & \multirow{2}{*}{129.8} & 6.07 \\
\hline & & PM & 118.6 & & 9.51 \\
\hline \multicolumn{6}{|c|}{ V-NOTCHED ROUNDED BAR } \\
\hline Angle $(2 \alpha)$ & $\begin{array}{c}\text { Tip radius } \rho \\
\mathrm{mm}\end{array}$ & Method & $\begin{array}{c}K_{\mathrm{c}}^{\text {theor. }} \\
\mathrm{MPa} \cdot \mathrm{m}^{(1-\lambda 1)}\end{array}$ & $\begin{array}{c}K_{\mathrm{c}}^{\exp } \\
\mathrm{MPa} \cdot \mathrm{m}^{(1-\lambda 1)}\end{array}$ & $\begin{array}{c}\text { Error } \\
\%\end{array}$ \\
\hline \multirow{2}{*}{$60^{\circ}$} & \multirow{2}{*}{0.39} & LM & 144.2 & \multirow{2}{*}{116.8} & -19.02 \\
\hline & & PM & 138.0 & & -15.37 \\
\hline \multirow{2}{*}{$90^{\circ}$} & \multirow{2}{*}{0.59} & LM & 215.4 & \multirow{2}{*}{157.7} & -26.77 \\
\hline & & PM & 207.1 & & -23.83 \\
\hline
\end{tabular}


occurs at lower values of the stress intensity factor than the prediction considered. Although the literature presents better results for failure prediction of $\mathrm{V}$-notched specimens, i.e., up to $7 \%{ }^{20}$, error estimates falling within the $\pm 20 \%$ interval are considered successful ${ }^{13,32}$. Moreover, $L$ and $\sigma_{0}$ used in failure prediction of $\mathrm{V}$-notched specimens under tensile stress were obtained from tests of U-notched specimens under bending loading and, as previously stated, notched AISI 420 under bending loading exhibited numerous microcracks, which did not occur in specimens under tensile stress.

\section{Conclusions}

$\sigma_{\mathrm{u}, \mathrm{t}}$ and $K_{\mathrm{Ic}}$ obtained using standard tests with tensile specimens did not result in appropriate values of $L$ and $\sigma_{0}$, which were unable to properly estimate the critical stress intensity factor for U-notched specimens under bending at failure.

Significant errors were associated with the presence of nonlinear phenomena, such as localized plastic deformation and, mainly, extensive microcracking. The microscopic evaluation of fracture was proven to be important for understanding the results.

Otherwise, $\sigma_{0}$ and $L$ determined from stress field analysis of U-notched specimens under bending loading (based on the conceptual formulation of PM and LM) enabled accurate failure prediction with errors lower than $\pm 1 \%$. Stress field analysis was proven to be able to consider nonlinear phenomena.

Similarly, $\sigma_{0}$ and $L$ were used to predict the failure of $\mathrm{V}$-notched specimens, with the results for plates under bending successfully obtained. However, poor predictions of V-notched rounded bars under tensile stress were obtained, which can be related to the absence of microcracks in specimens under tensile stress.

The results highlight that exploratory studies intended to assess the applicability of TCD in predicting failure should be supported by a comprehensive evaluation of fracture features.

\section{References}

1. Torabi AR. Estimation of tensile load-bearing capacity of ductile metallic materials weakened by a V-notch: the equivalent material concept. Mater Sci Eng A. 2012;536:249-55.

2. Louks R, Askes H, Susmel L. A generalized approach to rapid finite element design of notched materials against static loading using the Theory of Critical Distances. Mater Des. 2016;108:76079.

3. Neuber H. Theory of notch stresses: principles for exact calculation of strength with reference to structural form and material. 2nd ed. Berlin: Springer Verlag; 1958.

4. Peterson RE. Notch sensitivity. In: Sines G, Waisman JL, editors. Metal fatigue. New York: McGraw Hill; 1959. p. 293-306.

5. Whitney JM, Nuismer RJ. Stress fracture criteria for laminated composites containing stress concentrations. J Compos Mater. 1974;8:253-65.

6. Taylor D. Geometrical effects in fatigue: a unifying theoretical model. Int J Fatigue. 1999;21:413-20.

7. Taylor D. The theory of critical distances: a new perspective in fracture mechanics. 1st ed. London: Elsevier; 2007.

8. Taylor D. The theory of critical distances. Eng Fract Mech. 2008;75:1696-705.

9. Taylor D, Merlo M, Pegley R, Cavatorta MP. The effect of stress concentrations on the fracture strength of polymethylmethacrylate. Mater Sci Eng A. 2004;382(1-2):288-94.
10. Gómez FJ, Guinea GV, Elices M. Failure criteria for linear elastic materials with U-notches. Int J Fract. 2006;141:99-113.

11. Taylor $\mathrm{D}$. The theory of critical distances applied to the prediction of brittle fracture in metallic materials. Struct Integr Durab. 2005;1:145-54.

12. Susmel L, Taylor D. On the use of the Theory of Critical Distances to predict static failures in ductile metallic materials containing different geometrical features. Eng Fract Mech. 2008;75:4410-21.

13. Li W, Susmel L, Askes H, Fangfang L, Zhou T. Assessing the integrity of steel structural components with stress raisers using the Theory of Critical Distances. Eng Fail Anal. 2016;70:73-89.

14. Prieto G, Tuckart WR, Ipiña JEP. Influence of cryogenic treatment on fracture toughness of an AISI 420 Martensitic Stainless Steel. Mater Technol. 2017;51(4):591-6.

15. Barlow LD, Du Toit M. Effect of austenitizing heat treatment on the microstructure and hardness of martensitic stainless steel AISI 420. J Mater Eng Perform. 2012;21:1327-36.

16. ASM International. Handbook ASM: heat treating. Materials Park: ASM International; 2004. (vol. 4).

17. Garcia C, Alvarez LF, Carsi M. Effects of heat-treatment parameters on non-equilibrium transformations and properties of X45Cr13 and X60 Cr14MoV martensitic stainless steel. Weld Int. 1992;6:612-21.

18. Creager M, Paris PC. Elastic field equations for blunt cracks with reference to stress corrosion cracking. Int J Fract Mech. 1967;3:247-52.

19. Ayatollahi MR, Torabi AR. Brittle fracture in rounded-tip V-shaped notches. Mater Des. 2010;31:60-7.

20. Torabi AR. On the use of the Equivalent Material Concept to predict tensile load-bearing capacity of ductile steel bolts containing V-shaped threads. Eng Fract Mech. 2013;97:136-47.

21. Filippi S, Lazzarin P, Tovo R. Developments of some explicit formulas useful to describe elastic stress fields ahead of notches in plates. Int J Solids Struct. 2002;39:4543-65.

22. Lazzarin P, Filippi S. A generalized stress intensity factor to be applied to rounded V-shaped notches. Int J Solids Struct. 2006;43:2461-78.

23. American Society for Testing \& Materials - ASTM. ASTM E8/E8M: standard test methods for tension testing of metallic materials. West Conshohocken: ASTM International; 2016.

24. American Society for Testing \& Materials - ASTM. ASTM E399: standard test method for linear-elastic plane-strain fracture toughness KIc of metallic materials. West Conshohocken: ASTM International; 2017.

25. Krishna SC, Tharian KT, Chakravarthi KVA, Jha AK, Pant B. Heat treatment and thermo-mechanical treatment to modify carbide banding in AISI 440C steel: a case study. Metall Microstruct Anal. 2016;5(2):108-15.

26. Verhoeven JD. A review of microsegregation induced banding phenomena in steels. J Mater Eng Perform. 2000;9:286-96.

27. Porter DA, Easterling KE. Phase transformations in metals and alloys. 2nd ed. Cheltenham: Chapman \& Hall; 1992. 528 p.

28. Isfahany AN, Saghafian H, Borhani G. The effect of heat treatment on mechanical properties and corrosion behavior of AISI420 Martensitic Stainless Steel. J Alloys Compd. 2011;509:3931-6.

29. Hetzner DW, Van Geertruyden W. Crystallography and metallography of carbides in high alloy steels. Mater Charact. 2008;59(7):825-41.

30. American Society for Testing \& Materials - ASTM. ASTM E646: standard test method for tensile strain-hardening exponents (n-values) of metallic sheet materials. West Conshohocken: ASTM International; 2016.

31. Shivakumar KN, Crews JH Jr. Energy dissipation associated with crack extension in an elastic-plastic material. Eng Fract Mech. 1987;28:319-30.

32. Susmel L, Taylor D. The Theory of Critical Distances as an alternative experimental strategy for the determination of KIC and $\Delta$ Kth. Eng Fract Mech. 2010;77:1492-501. 